\title{
POLITICA DE TRABALHO DA ASSOCIAÇÃO BRASILEIRA DE ENFERMAGEM (ABEn)
}

\author{
A. C. Carvalho * \\ I - ABEn CARACTERIZAÇAO E OBJETO
}

\section{Introdução}

A Associação Brasileira de Enfermagem (ABEn), fundada em 12 de agosto de 1926, congrega enfermeiras/os brasileiras/os, ou estrangeiras/os radicadas/os ** no País, com o objetivo de incentivar o espírito de união e a cordialidade entre seus membros e entre esses e os representantes de profissões afins, e de pugnar pelo desenvolvimento da enfermagem em todos os seus ramos, através do aprimoramento das enfermeiras, individualmente, e do aperfeiçoamento dos programas de formação do pessoal de enfermagem.

A defesa da classe e dos interesses sócio-econômicos dos membros, o zelo pela observância de alto padrão de ética profissional, bem como a cooperação com as autoridades na solução de problemas profissionais ou educacionais relacionados com a enfermagem, constituem parte fundamental do seu programa de atividades.

Funciona como uma federação constituída pelas Seções Estaduais que, por sua vez, podem congregar Distritos, que são núcleos regionais ou municipais de enfermeiras, todos regidos por um único documento legal, os Estatutos da Associação Brasileira de Enfermagem e o seu Regulamento.

Da diretoria da ABEn, constituída por elementos com responsabilidades administrativas e executivas (presidentes. vice-presidentes, secretárias e tesoureiras) e pelas coordenadoras das suas Comissões T'écnicas (de Assistência de Enfermagem, Documentação e Estudo,

* Presidente de Associação Brasileira de Enfermagem. Trabalho apresentado na 1." Assembléia de Delegados de 1971; baseado em trabalhos anteriores sobre o mesmo assunto já publicado na RBEn.

** Daqui por diante será usado apenas a palavra "enfermeiras" para designar os profissionais de ambos os sexos, dada a porcentagem diminuta do elemento do sexo masculino na profissão e na Associação. 
Educação, Legislação e da Revista Brasileira de Enfermagem), emanam as diretrizes para o bom funcionamento das Seções Estaduais, de maneira a ser preservada a unidade de pensamento com relação à filosofia e à política de trabalho da Associação.

Seu órgão deliberativo, a Assembléia de Delegados, constituídas por representantes das Seções em número proporcional ao número de associados quites, é soberana nos seus julgamentos e nas suas decisões.

Como única entidade de classe representativa das enfermeiras brasileiras, assume o seu papel: na liderança e na coordenação das atividades de caráter cultural e assistencial programados no campo de enfermagem nacional; no assessoramento das autoridades ligadas à educação, à saúde e ao trabalho na discussão e na resolução de problemas ligados ao ensino e ao exercício profissional; na implementação de novos programas para enfermeiras nos campos da saúde e do bem-estar social; no desenvolvimento de uma comunicação eficiente e no intercâmbio de informações entre as enfermeiras e entre essas e a sua associação de classe; no provimento de assistência e aconselhamento às Seções e Distritos, quando solicitado.

A Associação Brasileira de Enfermagem é o porta-voz natural da enfermagem brasileira em âmbito nacional e internacional.

$\mathrm{Na}$ esfera internacional está filiada e mantém intercâmbio com o Conselho Internacional de Enfermeiros (ICN), com o Comitê Internacional Católico de Enfermeiras e Assistentes Médico-Sociais (CICIAMS e com a Federação Panamericanas de Enfermeiras/os.

$\mathrm{Na}$ qualidade de membro efetivo do Conselho Internacional de Enfermeiras apoia e endossa os princípios básicos defendidos por esse Conselho e que norteiam suas atividades internacionais.

\section{Pessoal de Enfermagem}

A Associação Brasileira de Enfermagem aceita a sugestão da Organização Mundial de Saúde relativa à divisão do pessoal de enfermagem em três categorias (1) e coloca a enfermeira, o técnico de enfermagem e o auxiliar de enfermagem respectivamente nas categorias I, II, III. Admite, não obstante, que o atendente vem prestando valiosa contribuição à assistência hospitalar no País e continuará a constituir o grupo mais numeroso, por cujo desenvolvimento a enfermeira deve assumir total responsabilidade.

(1) Organizacion Mundial de la Salud, Informe Técnico n.o 347 (Quinto Informe), Genebra, 1966, p. 13. 


\section{Definiçõ̃es}

A ABEn, reconhecendo 0 valor $e$ a propriedade de conceitos relativos à enfermagem emitidas pela Organização Mundial de Saúde e pelo Conselho Internacional de Enfermeiras, vale-se de alguns deles para a definição de termos do presente documento.

Enfermagem - caracterizadas como sendo a "função peculiar da enfermeira, de prestar assistência ao indivíduo doente ou sadio no desempenho de atividades que contribuem para manter a saúde ou para recuperá-la (ou ter uma morte serena), atividades que ele desempenharia sozinho, se tivesse a força, vontade ou conhecimento necessários. E fazê-lo de modo que o ajude a recuperar sua independência o mais rapidamente possivel." (2)

Assistência de Enfermagem - consiste na adoção, pelo pessoal de enfermagem, de "medidas que visem a segurança, o conforto físico e mental, a recuperação e a reabilitação de pessoas enfermas, e a educação sanitária de sãọs e doentes." (3)

Enfermeira - pessoa que tenha completado o curso de enfermagem em escolas oficiais ou reconhecidas, de acordo com a legislação vigente, ou portadora de diploma estrangeiro conferido por escola reconhecida no País de origem, qualificada e autorizada, portanto, "para assumir a responsabilidade da assistência de enfermagem visando a promoção da saúde, a prevenção da doença e a prestação de cuidados ao enfermo." (4)

Técnico de Enfermagem - pessoa que tenha completado o curso Técnico de Enfermagem em colégios ou cursos of iciais ou reconhecidos de acordo com a legislação vigente, e "capaz de prestar assistência de enfermagem de natureza menos complexa e que exige competência técnica e habllidade em relações inter-pessoais. A pessoa pertencente a esta categoria deverá estar qualificada a prestar assistência de natureza preventiva, curativa e de reabilitação, levando em consideração as necessidades psicológicas e sociais dos indivíduos." (5)

Auxiliar de Enfermagem - pessoa qce tenha completado o curso regular ou o curso intensivo de auxiliar de enfermagem oficiais ou reconhecidos de acordo com a legislação vigente, e "capaz

(2) Henderson, Virgínia: Princípios Básicos sobre Cuidados de Enfermagem. Rio, ABEn, 1962, p. 4. Definição adotada pelo Conselho Internacional de Enfermeiras.

(3) Curso de Enfermagem - Relatório da Comissão de Peritos. RBEn, 16 (1): 6-11, 1963.

(4) Conselho Internacional de Enfermeiras - Documentos Básicos (1965).

(5) Organizacion Mundial de la Salud, Informe Técnico n. 347 (Quinto Informe), Genebra, 1966, p. 13. 
de executar tarefas especificas relacionadas com a assistência de enfermagem e que requeiram menor capacidade de julgamento. Os que pertencem a esta categoria devem estar capacitados a manter bom relacionamento com os pacientes e a executar com segurança, sob supervisão, as tarefas para as quais foram treinados.' (6)

Equipe de Enfermagem - formada pelas três categorias de pessoal de enfermagem com a inclusão eventual do atendente, para a integração do trabalho com o fim de melhorar a assistência, quantitativa e qualitativamente.

\section{iI - filosofia e pRINCtPios basicos}

A Associação Brasileira de Enfermagem assume a responsabilidade de contribuir efetivamente para o desenvolvimento do ensino e do exercício da enfermagem na País e para o aprimioramento individual de seus membros. Ao indicar diretrizes que conduzam ao aperfeiçoamento desses programas norteia-se por crenças e princípios sólidos, fundamentais à consecução de um dos mais importantes dos seus propósitos, o de colaborar para a melhoria da assistência de saúde ao povo brasileiro.

Fundamenta seus princípios e ações na Constituição do Brasil, cuja filosofia ressalta a formação e a valorização humana, o reconhecimento da igualdade de direitos entre os cidadãos, o incentivo para o crescimento individual e coletivo, a ampla participação na vida nacional e o direito inalienável do homem na produção e na utilização dos bens sociais.

Baseada no seu Código de tica e em seus estatutos, os quais regulamentam seus fins e suas ações, e em consonância com a Declaração Universal dos Direitos do Homem, a Associação Brasileira de Enfermagem reconhece que a enfermagem, por sua natureza, tem como objetivo central o homem em sua dignidade absoluta; como atividade humana universal, rege-se por normas éticas e se desenvolve de acordo com o progresso científico e tecnológico; e, como profíssão, constitui um grupo social que no contexto sócio-econômico e cultural do País coordena-se com as demais no sentido de contribuir para o bem estar comum. Declara sua crença em que:

- Todo ser humano tem direito à saúde e, portanto, a uma assistência de enfermagem que lhe assegure a proteção ou, em caso de perda, a recuperação de sua saúde.

(6) Ibid, p. 13.

NOTA Os enfermeiros práticos e os práticos de enfermagem podem exercer as mesmas funçőes dos auxilliares de enfermagem (Decreto n. ${ }^{\circ}$ 50.387/61 que regulamenta o exercício de enfermagem no Pais). 
- A assistência de enfermagem inclui os aspectos preventivos, curativos, de reabilitação e de apoio psicológico, religioso e social, planejada segundo as necessidades de cada indivíduo ou grupo da comunidade.

- A assistência de enfermagem envolve atividades de complexidade diversa e de diferenciado grau de responsabilidade, o que permite ser realizada por uma equipe constituída por elementos de enfermagem de diferentes níveis, sob supervisão da enfermeira.

- A contribuição da enfermeira no campo de saúde é de grande importância para a manutenção da eficiência dos serviços que as instituições de saúde oferecem à comunidade.

- O exercício profissional tem como imperativo atender às necessidades do País, conforme sua realidade sanitária, e à demanda do mercado de trabalho.

- A comunidade tem participação decisiva no desenvolvimento da profissão, pois ao reconhecer sua importância e exigir melhores padrões de assistência, influi na demanda de pessoal de enfermagem, na sua formação e no seu aperfeiçoamento.

- E fundamental para a enfermagem o emprego da pesquisa aplicada e de estudos operacionais a fim de promover as mudanças metodológicas indispensáveis à educação e ao exercício profissional.

- Os estudos pós-graduados e a especialização dos profissionais de enfermagem são condições essenciais para o aperfeiçoamento da prática profissional.

- O sistema educacional adotado pelo País para o preparo da enfermeira, e o controle do exercício profissional, influenciam a qualidade da assistência de enfermagem.

- O ensino da enfermagem é realizado com maior eficiência em instituições que tenham a educação como finalidade principal.

- A formação pedagógica e o aperfeiçoamento continuado do corpo docente das escolas de enfermagem são requisitos fundamentais para a dinamização e a atualização do ensino.

- A enfermeira tem direito a justa remuneração e a condições de trabalho satisfatórias, compatíveis com o seu nível de preparo, carga de trabalho e grau de responsabilidade.

Baseada em suas conviç̧ões a Associação Brasileira de Enfermagem declara como princípios básicos para o exercício e o ensino da enfermagem:

1. A função primária da enfermeira é prestar serviço ao público, sob a forma de assistência de enfermagem a indivíduos ou a grupos de comunidade, sem restrições a nacionalidade, raça, cor, credo político ou religioso e status social.

2. Constitui responsabilidade individual da enfermeira conhecer as necessidades de saúde do País nos níveis local, regional e 
nacional, e organizar suas atividades de modo a colaborar no atendimento daquelas necessidades.

3. A colaboração no planejamento dos serviços de enfermagem nos niveis nacional e regional, faz parte das atribuiçōes da enfermeira.

4. A existência de um órgão fiscalizador do exercício profissional contribui para a melhoria da qualidade dos serviços prestados e para a proteção da comunidade servida.

5. O atendente, elemento provisòriamente indispensável na equipe de enfermagem, deve receber treinamento prévio suficiente, e contar com educação continuada que o capacite a colaborar eficientemente na assistência de enfermagem.

6. Um sistema organizado de serviço de enfermagem em que o pessoal é utilizado no máximo de sua capacidade é condição indis: pensável para a eficiência da assistência prestada e para o desenvolvimento da profissão.

7. A enfermeira por seu nível de formação e pelas possibilidades de estudos avançados em administração de enfermagem, é o profissional indicado para exercer a direção dos serviços de enfermagem.

8. O estudante de enfermagem, seu desenvolvimento como pessoa, cidadão e profissional, constitui o centro em torno do qual todas as atividades da escola devem ser programadas.

9. O curso de graduação em enfermagem deve preparar o enfermeiro para, como líder natural da equipe de enfermagem, exercer as funções de enfermagem propriamente ditas, funçōes médicas delegadas, de coordenação da equipe, de ensino e supervisão de pessoal auxiliar e de planejamento e assessoria de enfermagem em nivel local.

10. O currículo de graduação em enfermagem deve incluir uma parte básica compreendendo as ciências humanas, bio-físicas e psicosociais e uma parte profissionalizante centralizada na enfermagem e fundamentada nas ciências médicas e do comportamento; deve ser planejado levando em conta as necessidades globais de saúde do povo brasileiro e a sua bagagem sócio-cultural, acompanhando o progresso das ciências educacionais, sociais, médicas e, sobretudo, apresentando flexibilidade a fim de corresponder às necessidades regionais de saúde; deve compreender ensino teórico e prático em que sejam utilizados os modernos métodos pedagógicos, incluindo experiências clínicas adequadas, orientadas e supervisionadas, nas quais a assistência de enfermagem seja de boa qualidade; o desenvolvimento da capacidade crítica e de investigação do estudante constitui a base para o aperfeiçoamento posterior da enfermeira, em cursos de especialização e de pós-graduação. 
11. O preparo do técnico de enfermagem deve ser feito em instituições educacionais e é essencial que o curriculo inclua o ensino teórico e prático das disciplinas fundamentais de enfermagem de modo a habilitar o profissional a prestar a assistência de enfermagem preventiva, curativa e de reabilitação com conhecimento e competência técnica.

12. O preparo do auxiliar de enfermagem deve apoiar-se em programa essencialmente prático que o habilite a colaborar na assis. tência de enfermagem executando tarefas específicas, sob supervisão.

13. A enfermeira, por seu nível de formação e por possuir conhecimentos especializados de enfermagem com possibilidades de estudos pós-graduados, é o profissional indicado para a ministração do ensino teórico e prático das disciplinas profissionais e para a direção dos cursos de enfermagem dos três níveis, de graduação, técnico e de auxiliar de enfermagem.

14. As enfermeiras têm o direito de lutar por melhores salários e melhores condições de trabalho; devem, portanto, integrar-se em associação profissional da classe que se responsabilizará pela defesa de seus interesses econômicos e profissionais.

15. Enquanto não existirem o Conselho de Enfermagem, e o Sindicato de Enfermeiras Diplomadas, cabe à Associação Brasileira de Enfermagem a responsabilitdade de zelar pela conservaçãa de alto padrão de ética profissional e pela defesa dos interesses e direitos da classe. 